\title{
INVESTIGATION OF THE PROCESS WINDOW FOR DEFORMATION INDUCED FERRITE TO IMPROVE THE JOINABILITY OF PRESS-HARDENED COMPONENTS
}

\author{
${ }^{1}$ Bernd-Arno BEHRENS, ${ }^{1}$ Kai BRUNOTTE, ${ }^{1}$ Hendrik WESTER, ${ }^{*}$ Eugen STOCKBURGER \\ 1'Institute of Forming Technology and Machines, Leibniz Universität Hannover, 30823 Garbsen, Deutschland \\ stockburger@ifum.uni-hannover.de
}

https://doi.org/10.37904/metal.2020.3523

\begin{abstract}
Due to their high tensile strengths increasing the crashworthiness of the vehicles, ultra-high strength steels are increasingly used in the automotive industry, for example in components like B-pillars or tunnel. 22MnB5 is a premier candidate for this cause, since it can be press-hardened and phase-transformed into the martensitic phase, resulting in high hardness and tensile strength. However, complications can arise in the assembly of press-hardened components since conventional mechanical joining processes have their limitations due to high forces required for joining press-hardened steels, especially in multi-sheet layers. Therefore, this study focuses on the determination of an optimum process window to influence the 22MnB5 microstructure thermo-mechanically during press hardening, causing a local softening. This so-called deformation-induced ferrite improves ductility at the desired locations to ease the mechanical joining operation in the assembly. Investigations are performed on a forming dilatometer varying the cooling rate, the introduced amount of plastic strain and the forming temperature along with metallographic as well as microhardness measurements. Based on the laboratory tests, a process window of the deformation induced ferrite is derived for an application in a forming press.
\end{abstract}

Keywords: Press hardening, manganese boron steel, deformation induced ferrite

\section{INTRODUCTION}

Major focus in the automotive industry in recent times is to reduce energy consumption and emissions while improving crashworthiness and driving safety. This can be achieved by making the vehicle lighter through removing additional weight or using materials with high strength to weight ratios [1]. Press hardening, also known as hot stamping, is a combination of hot forming and a heat treatment in the forming tools. Ultra-high strength steels like 22MnB5 can be formed into complex shapes, which is not possible with regular cold forming operations. The applied press-hardened components in the automotive industry are chassis components like A-pillar, B-pillar, bumper, roof rail, rocker rail and tunnel [2]. For press hardening 22MnB5, the sheet metal is first heated in an oven to a temperature above austenitisation temperature, such as $930^{\circ} \mathrm{C}$. The sheet is held at this temperature for a certain time, in general $6 \mathrm{~min}$, to ensure a fully austenised material and a sufficient diffusion of the AISi coating. Afterwards, the sheet is transferred to a forming press, hot deep drawn and subsequently cooled in the forming tool. The critical cooling rate of 22MnB5 to induce diffusionless martensitic transformation is $27^{\circ} \mathrm{C} / \mathrm{s}$. The resulting martensitic structure is responsible for the high strength of the component around 1,500 MPa. However, components with high strength properties are difficult to join mechanically and they may not provide sufficient connections especially in multi-sheet joints [3]. Therefore, special techniques have been developed to obtain tailored properties in a given component by varying the austenitisation approach, by modifying the quenching process or by adding an annealing step after cooling. Another possibility to change the microstructure transformation behaviour of steels is a mechanical treatment at high temperatures. Due to a deformation of an austenised material, the phase areas in the continuous cooling transformation diagram are shifted to lower times. In order to achieve a completely martensitic 
microstructure in $22 \mathrm{MnB} 5$ for a deformation of $10 \%$ at $800{ }^{\circ} \mathrm{C}$, a critical cooling rate of $50{ }^{\circ} \mathrm{C} / \mathrm{s}$ instead of $27^{\circ} \mathrm{C} / \mathrm{s}$ is required as shown in Figure 1 [4].
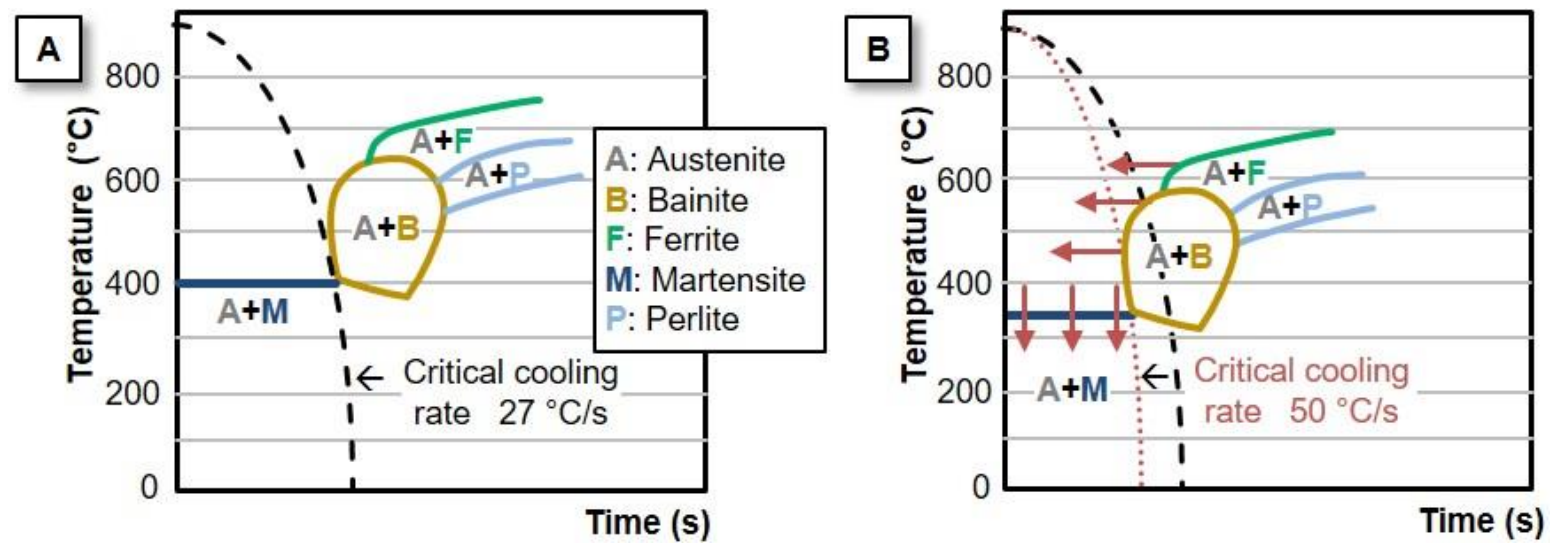

Figure 1 Continuous cooling transformation diagram of 22MnB5: (A) without deformation and (B) with $10 \%$ deformation at $800^{\circ} \mathrm{C}$ of the austenised material according to [4]

Furthermore, the formation of ferrite above the actual ferrite start temperature is possible. Ferrite formed this way is called deformation induced ferrite (DIF) [5]. By forming the austenite, some of the deformation energy is stored in it, lowering the nucleation energy and leading to DIF formation [6]. Various parameters influence the DIF creation besides the cooling rate, such as the forming temperature and the amount of plastic strain. As the forming temperature decreases, the amount of DIF increases. This is due to the increase in flow stress with decreasing temperature. Therefore, a higher force is required to form the material, increasing the deformation energy stored in the austenite. Min et al. determine the DIF creation after austenitisation between forming temperatures of $600-800{ }^{\circ} \mathrm{C}$ [7]. The highest amount of DIF is at $600{ }^{\circ} \mathrm{C}$ and the lowest DIF content is measured at forming temperatures of $800^{\circ} \mathrm{C}$. No DIF is formed at $900{ }^{\circ} \mathrm{C}$. Regarding the amount of plastic strain, the DIF creation increases with higher plastic strain due to the increase in dislocations in the microstructure and thus to an increase in the stored deformation energy [8].
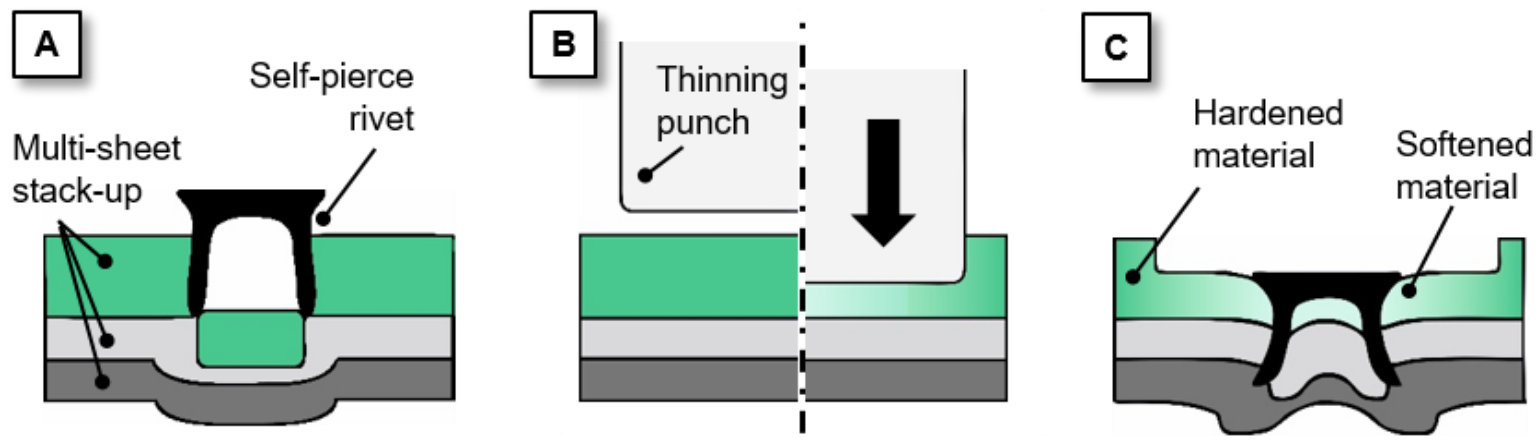

Figure 2 (A) Initial conditions for self-pierce riveting, (B) creating the local softening in the austenised material and $(\mathrm{C})$ joining with adapted mechanical properties according to [3]

In this study, the effect of DIF creation will be used to locally deform the sheet material prior to martensite formation in order to achieve softer areas, as shown in Figure 2. The deformation will be carried out in the flange of the component directly after hot deep drawing and before die quenching. The local DIF creation and therefore softening improves mechanical joining like self-pierce riveting. Therefore, parameters such as the forming temperature, the amount of plastic strain and the cooling rate, have been varied in dilatometric experiments to investigate an optimal process window for applying the local deformation in the 22MnB5 component after hot deep drawing. 


\section{DILATOMETRIC METHODOLOGY}

To analyse the effect of different parameters such as the cooling rate, the amount of introduced plastic strain and the forming temperature on the manganese boron steel $22 \mathrm{MnB} 5$, dilatometric experiments are conducted using the quenching and forming dilatometer DIL 805A/D+T from TA Instruments in tension mode (Figure 3 A). The specimen measuring area is $1.5 \times 3 \times 10 \mathrm{~mm}$, in which the blank thickness is $1.5 \mathrm{~mm}$ and the length in rolling direction is $10 \mathrm{~mm}$. The detailed dimensions of the specimens are also shown in Figure $3 \mathbf{A}$. The specimens are cut by water jet. A thermocouple with a diameter of $0.2 \mathrm{~mm}$ is spot welded in the middle of the specimen's surface to control the specimen's temperature. In the dilatometer, the specimens are heated to $930{ }^{\circ} \mathrm{C}$ with a constant heating rate of $15^{\circ} \mathrm{C} / \mathrm{s}$ and kept for $6 \mathrm{~min}$ to obtain uniform austenite in the steel. The specimen is then cooled to different forming temperatures $T 500,600,700$ and $800^{\circ} \mathrm{C}$ with $15^{\circ} \mathrm{C} / \mathrm{s}$, at which the deformation is induced. The amount of plastic strain $\varepsilon$ in the specimen is also varied from $0,0.1,0.2$ and 0.3 at a constant strain rate of $0.2 \mathrm{~s}^{-1}$. To study the phase transformation from austenite to martensite, bainite, perlite and ferrite, the cooling rate $\dot{T}_{\mathrm{C}}$ of 20,50 and $80^{\circ} \mathrm{C} / \mathrm{s}$ is chosen. Figure $3 \mathbf{B}$ shows the experimental scheme of the dilatometric study to examine the effects of different process parameters on the hardness of the sample. The values are chosen based on the industrial process route of press hardening 22MnB5. For each parameter combination, five specimens are tested to ensure a statistical security.
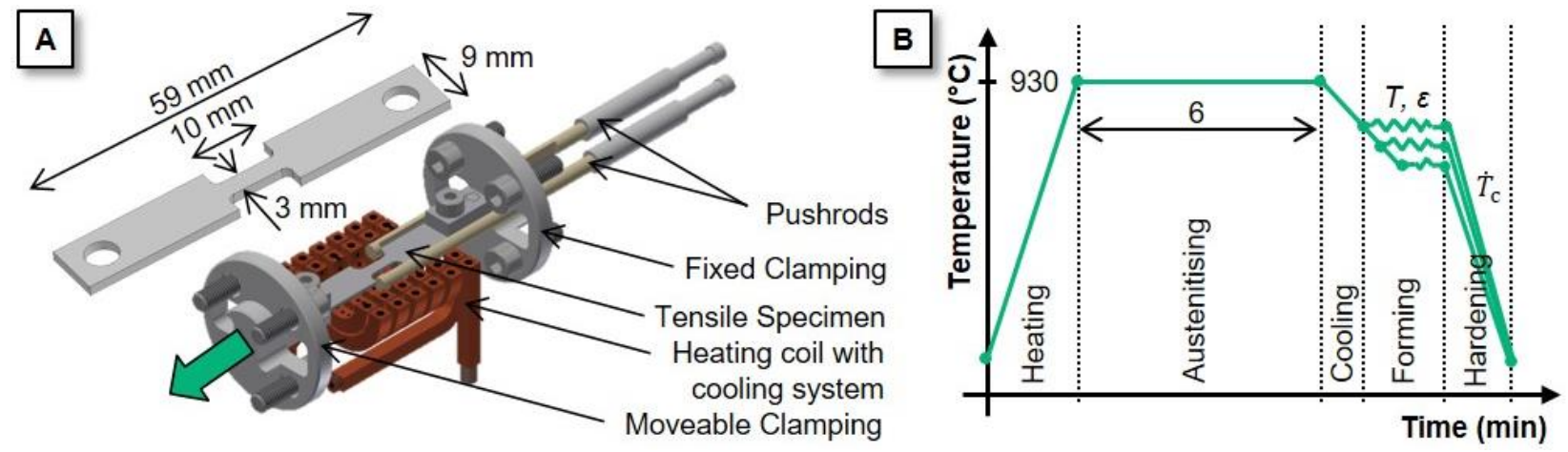

Figure $3(A)$ Forming dilatometer in tension mode with specimen dimensions and $(B)$ temperature-time history of the tensile tests with the state variables of the process

Metallography of the thermo-mechanically treated specimens is performed to analyse the phases regarding the resulting microstructures. The metallographic specimens are cut from the middle region of the dilatometric specimen at the position of the thermocouple by wet cut-off grinding. Subsequently, the metallographic specimens are mounted in epoxy resin and polished to a mirror finish by using 2000, 1200 and $500 \mathrm{~mm}$ grit $\mathrm{SiC}$ paper followed by 0.003 and $0.001 \mathrm{~mm}$ diamond paste. A $4 \mathrm{wt} \%$ nitric acid alcohol solution is used to reveal the microstructure. The micrographic observation is performed on the Neophot30 optical microscope. The Vickers hardness is measured using a MH-3 microhardness tester according to HV0.1 and the hardness is taken through the thickness direction with five locations selected in the middle of the specimen. The mean value of hardness is thus determined and taken as the hardness value in HV0.1.

\section{RESULTS AND DISCUSSION}

The initial microstructure of the $22 \mathrm{MnB} 5$ sheet is shown in Figure $4 \mathrm{~A}$. A fine-grained ferritic-perlitic texture is visible. The tensile specimens are firstly heat treated as described and to display the effect of DIF creation, first parameters from literature are tested. Therefore, a cooling rate, such as $50^{\circ} \mathrm{C} / \mathrm{s}$, higher than the critical one $\left(27^{\circ} \mathrm{C} / \mathrm{s}\right)$ is chosen after forming at $700^{\circ} \mathrm{C}$ and the amount of plastic strain is set to 0 and 0.3 . For the undeformed sample, a fully martensitic microstructure is observed and for an amount of plastic strain of 0.3 , creation of DIF can be detected (white coloured areas). Further, the cooling rate is set lower than the critical cooling rate, such as $20^{\circ} \mathrm{C} / \mathrm{s}$, and the amount of plastic strain is varied from 0 to 0.3 . For the undeformed 
sample with a cooling rate of $20^{\circ} \mathrm{C} / \mathrm{s}$, a martensitic structure with some bainite is noticeable. By increasing the plastic strain to 0.3 , a lot of DIF can be detected. The investigations by the visual analyses can be confirmed by the hardness measurements in Figure $4 \mathrm{~B}$. The initial microhardness of the untreated material is $189 \mathrm{HV} 0.1$ and rises because of the heat treatment with cooling of $50^{\circ} \mathrm{C} / \mathrm{s}$ up to $451 \mathrm{HV} 0.1$. Forming at $700{ }^{\circ} \mathrm{C}$ introducing a plastic strain of 0.3 reduces the microhardness to $387 \mathrm{HV} 0.1$. If the specimen is cooled with $20^{\circ} \mathrm{C} / \mathrm{s}$ after the heat treatment, the resulting microhardness is $441 \mathrm{HV} 0.1$ and therefore marginally less than cooling with $50^{\circ} \mathrm{C} / \mathrm{s}$. By introducing a plastic strain of 0.3 at $700{ }^{\circ} \mathrm{C}$ and cooling with $20^{\circ} \mathrm{C} / \mathrm{s}$ the occurring microhardness is $283 \mathrm{HV} 0.1$ including a high amount of DIF. This illustrates very clearly the DIF effect and the influence of a deformation on phase transformations.
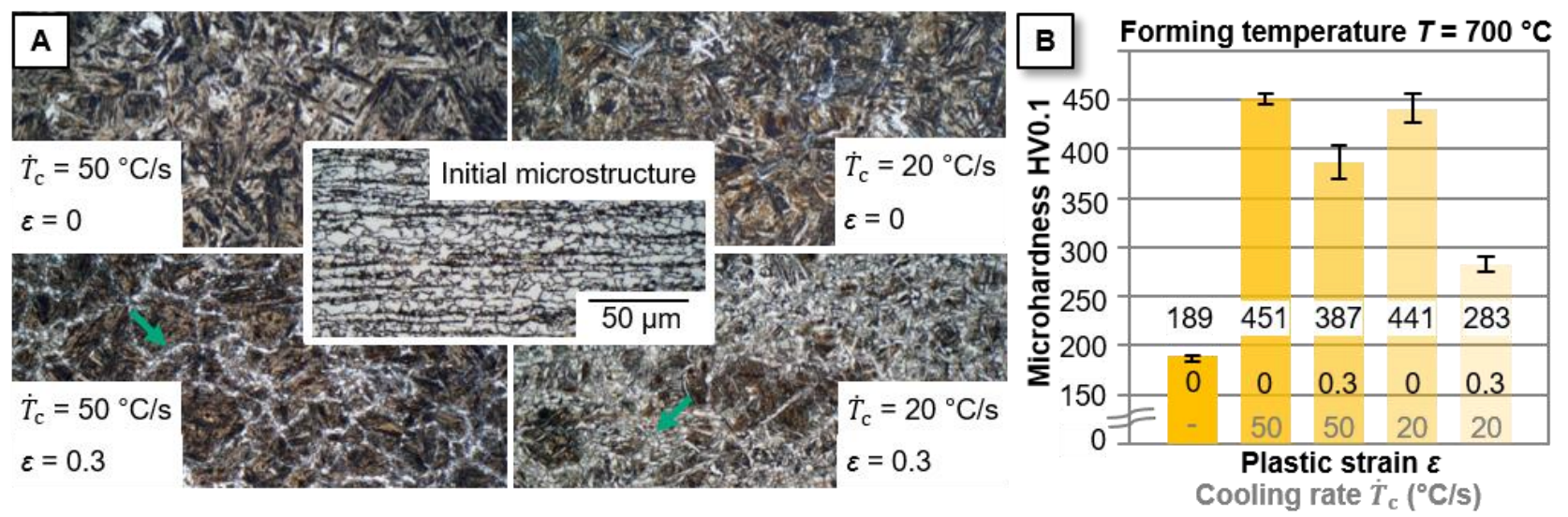

Figure 4 (A) Micrographs and (B) hardness with standard deviation for the initial microstructure, variation of the amount of plastic strain and of the cooling rate

Figure $5 \mathrm{~A}$ shows the microstructure of the specimens after undergoing the thermo-mechanical treatment in the dilatometers for various amounts of plastic strain at a constant forming temperature of $600{ }^{\circ} \mathrm{C}$ and a cooling rate of $80^{\circ} \mathrm{C} / \mathrm{s}$. The forming temperature is chosen as $600{ }^{\circ} \mathrm{C}$, since the temperature in the flange of a component after hot sheet metal forming can result in a temperature range of $500-600{ }^{\circ} \mathrm{C}$ [3]. The highest cooling rate is chosen as $80^{\circ} \mathrm{C} / \mathrm{s}$ due to the maximum cooling rate of the forming dilatometer in tension mode and due to the high cooling rates while press hardening.
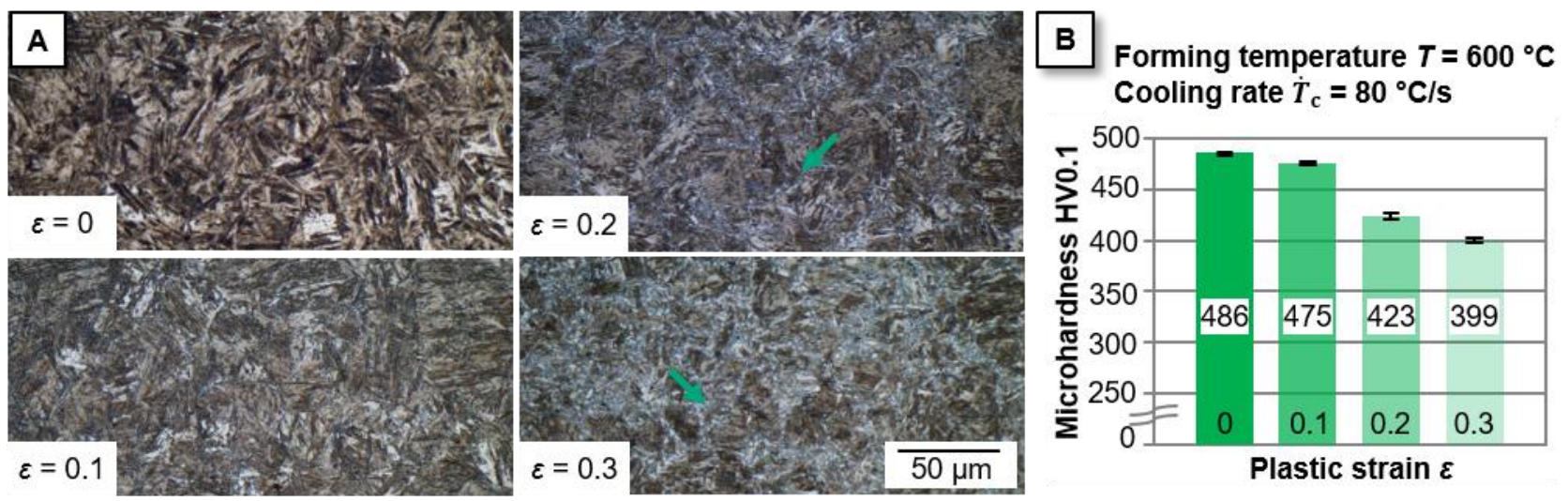
Cooling rate $\dot{T}_{\mathrm{c}}=80^{\circ} \mathrm{C} / \mathrm{s}$

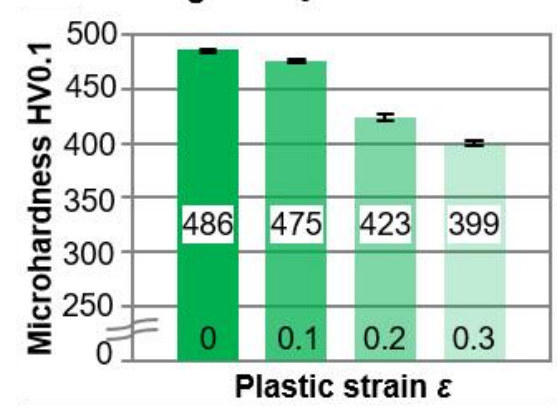

Figure 5 (A) Micrographs and (B) hardness with standard deviation for different amounts of plastic strain

For the undeformed specimen and for a plastic strain of 0.1 , a fully martensitic texture is obtained. For a plastic strain of 0.2 a combination of martensite and DIF occurs. With a higher amount of plastic strain, a consistent increase of DIF (white coloured areas) is observable. Increasing the amount of plastic strain from 0 to 0.3 leads to a decrease in the hardness also indicating a fewer content of the hard martensitic phase and a higher 
percentage of the softer DIF (Figure 5 B). Since a sharp drop of hardness values for plastic strains from 0.1 to 0.2 is noticeable, a plastic strain of at least 0.2 should be considered for the process application. Higher plastic strains might lead to excessive forming forces.

Based on further results, different forming temperatures are investigated using a plastic strain of 0.2 and a cooling rate of $80^{\circ} \mathrm{C} / \mathrm{s}$. The forming temperature is varied from $500-800^{\circ} \mathrm{C}$. The micrographs in Figure $6 \mathrm{~A}$ show an increase of the DIF (white coloured areas) from a forming temperature of $800{ }^{\circ} \mathrm{C}$ to $700^{\circ} \mathrm{C}$. The amount of white coloured areas stays constant for lower forming temperatures. The variation of the forming temperature leads to a gradual decrease in the average microhardness values from 486 to $420 \mathrm{HV} 0.1$ (Figure $6 \mathrm{~B}$ ). The drop from $800{ }^{\circ} \mathrm{C}$ to $700{ }^{\circ} \mathrm{C}$ is the highest by $38 \mathrm{HV} 0.1$. For forming temperatures up to $500^{\circ} \mathrm{C}$, the change in hardness is very marginal, almost constant due to statistical deviation. Therefore, the forming temperature of the application in the forming press should be around $600-700{ }^{\circ} \mathrm{C}$ to create a high amount of DIF and to reduce the forming forces.
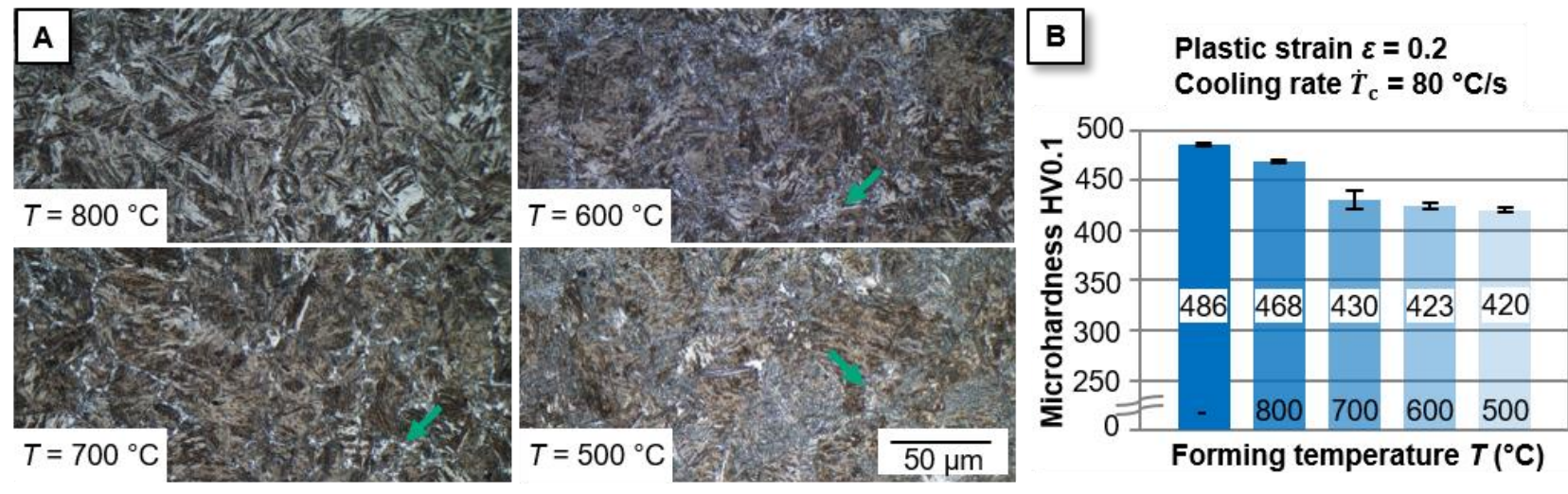

Figure 6 (A) Micrographs and (B) hardness with standard deviation for different forming temperatures

In Figure $7 \mathbf{A}$, the influence of the cooling rate is demonstrated. The amount of plastic strain is 0.2 and the forming temperature $600^{\circ} \mathrm{C}$. The forming temperature and the amount of plastic strain are defined based on prior conclusions. The highest cooling rate is chosen as $80^{\circ} \mathrm{C} / \mathrm{s}$ and subsequently reduced to $50{ }^{\circ} \mathrm{C} / \mathrm{s}$ and $20^{\circ} \mathrm{C} / \mathrm{s}$. The amount of DIF increases sharply as the cooling rate decreases from $80^{\circ} \mathrm{C} / \mathrm{s}$ to $20^{\circ} \mathrm{C} / \mathrm{s}$. The metallographic analysis of the samples shows an increase in the concentration of the DIF. For comparison, the specimen with maximal hardness (Cooling rate $80^{\circ} \mathrm{C} / \mathrm{s}$, plastic strain 0 ) is also depicted. The effect of the cooling rate is also displayed by the measurements in Figure $7 \mathrm{~B}$ as the hardness drops from $423 \mathrm{HV} 0.1$ to $291 \mathrm{HV} 0.1$ for a decrease of the cooling rates from $80^{\circ} \mathrm{C} / \mathrm{s}$ to $20^{\circ} \mathrm{C} / \mathrm{s}$.
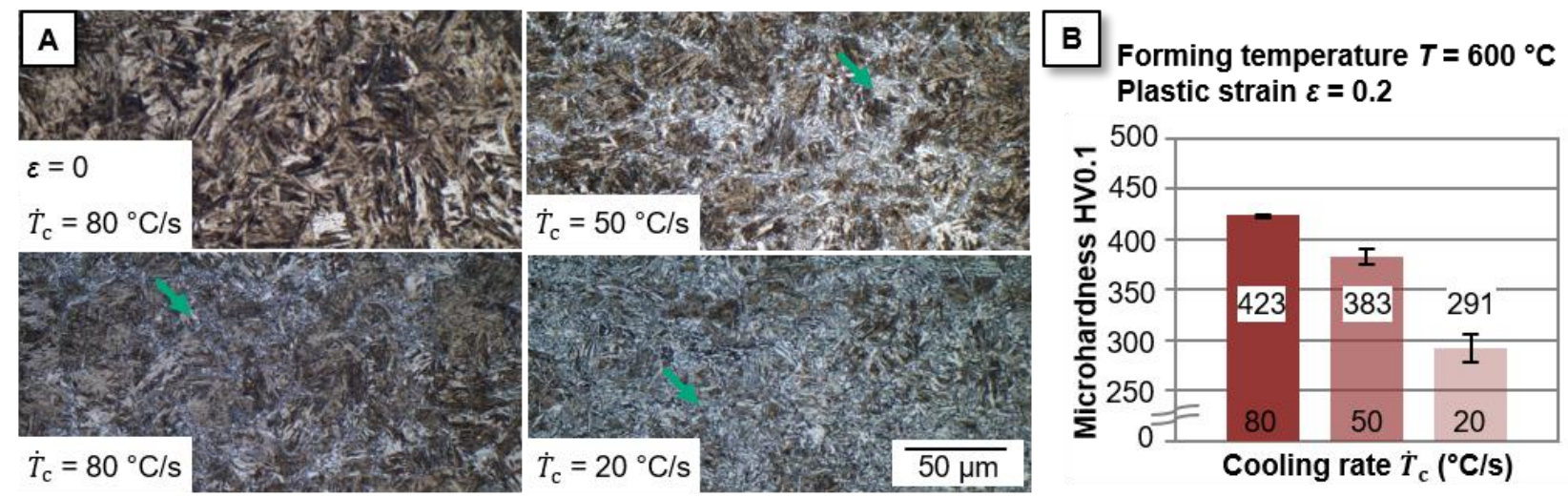

Figure $7(A)$ Micrographs and (B) hardness with standard deviation for different cooling rates 
The high decrease in hardness following a reduced cooling rate from $50{ }^{\circ} \mathrm{C} / \mathrm{s}$ to $20^{\circ} \mathrm{C} / \mathrm{s}$ is caused by falling below the critical cooling rate of $27^{\circ} \mathrm{C} / \mathrm{s}$. Obviously, the cooling rate has the biggest impact on the phase transformations and the DIF creation. Therefore, for the application in a forming machine, the cooling rate should be higher than the critical cooling rate of $27^{\circ} \mathrm{C} / \mathrm{s}$ to create martensite in the component, but as low as possible to locally create DIF in the desired areas. This leads to an optimal process window for the cooling rate in between $30-50{ }^{\circ} \mathrm{C} / \mathrm{s}$ introducing a plastic strain of at least 0.2 at a forming temperature of $600{ }^{\circ} \mathrm{C}$.

\section{CONCLUSION}

In this article, the influence of forming temperature, amount of plastic strain and cooling rate on the microstructure of 22MnB5 is experimentally studied via thermo-mechanical treatment of dilatometer specimens and metallographic as well as microhardness measurements of the treated specimens. A process window is established for the different parameters. The amount of plastic strain affects the DIF creation positively during the hardening of 22MnB5. A strain of at least 0.2 induces softness of significance required for the further use in multi-sheet joining. Also investigated in the study is the influence of forming temperature and a temperature of around $600{ }^{\circ} \mathrm{C}$ is chosen. Furthermore, a slow cooling rate between $30-50^{\circ} \mathrm{C} / \mathrm{s}$ is suggested. Therefore, areas in the component without plastic deformation will be hardened and with plastic deformation will be softer due to DIF. In further research, these parameters will be used to design a press hardening process of a component like B-pillar with local deformation to create DIF in certain areas to improve mechanical joinability.

\section{ACKNOWLEDGEMENTS}

The presented results are based on the framework of the research project "Local material influence during press hardening to improve the joinability of components made of 22MnB5" (grant number 19797 BG). The authors would like to thank the Research Association for Steel Application (FOSTA) and the German Federation of Industrial Research Associations (AiF) for the financial support.

\section{REFERENCES}

[1] STOCKBURGER, E., WESTER, H., UHE, J., BRUNOTTE, K., BEHRENS, B.-A. Investigation of the forming limit behavior of martensitic chromium steels for hot sheet metal forming. In: WULFSBERG, J., HINTZE, W., BEHRENS, B.A., eds. Production at the leading edge of technology. Berlin-Haidelberg: Springer Vieweg, 2019, pp. 159-168.

[2] KARBASIAN, H., TEKKAYA, A. E. A review on hot stamping. Journal of Materials Processing Technology. 2010, vol. 210, pp. 2103-2118.

[3] BEHRENS, B.-A., JÜTTNER, S., BRUNOTTE, K., ÖZKAYA, F., WOHNER, M., STOCKBURGER, E. Extension of the Conventional Press Hardening Process by Local Material Influence to Improve Joining Ability. Procedia Manufacturing. 2020, vol. 47, pp. 1345-1352.

[4] DRILLET, P., GRIGORIEVA, R., LEUILLIER, G., VIETORIS, T. Study of cracks propagation inside the steel on press hardened steel zinc based coatings. La Metallurgia Italiana. 2012, vol. 1, pp. 1-8.

[5] DONG, H. Deformation Induced Ferrite Transformation. In: WENG, Y., ed. Ultra-Fine Grained Steels. BerlinHeideberg: Springer Vieweg, 2009, pp. 86-136.

[6] DONG, H., SUN, X. Deformation induced ferrite transformation in low carbon steels. Current Opinion in Solid State and Materials Science. 2005, vol. 9, pp. 269-276.

[7] MIN, J., LIN, J. On the ferrite and bainite transformation in isothermally deformed 22MnB5 steels. Materials Science and Engineering A. 2012, Vol. 550, pp. 375-387.

[8] SOMANI, M. C., KARJALAINEN, L. P., ERIKSSON, M., OLDENBURG, M. Dimensional changes and microstructural evolution in a B-bearing steel in the simulated forming and quenching process. ISIJ International. 2001, vol. 41, pp. 361-367. 